Article

\title{
Improved Tribological Performance of Amorphous Carbon (a-C) Coating by $\mathrm{ZrO}_{2}$ Nanoparticles
}

\author{
Jinzhu Tang ${ }^{1,2}$, Qi Ding ${ }^{1,3, *}$, Songwei Zhang ${ }^{1,3}$, Guizhi $\mathrm{Wu}^{1}$ and Litian $\mathrm{Hu}{ }^{1, *}$ \\ 1 State Key Laboratory of Solid Lubrication, Lanzhou Institute of Chemical Physics, \\ Chinese Academy of Sciences, Lanzhou 730000, China; tangjinzhu11@163.com (J.T.); \\ zhangsw@licp.cas.cn (S.Z.); gzwu@licp.cas.cn (G.W.) \\ 2 University of Chinese Academy of Sciences, Beijing 100049, China \\ 3 Qingdao Center of Resource Chemistry and New Materials, Qingdao 266100, China \\ * Correspondence: dingqi@licp.cas.cn (Q.D.); lthu@licp.cas.cn (L.H.); \\ Tel.: +86-931-4968-833 (Q.D.); +86-931-4968-006 (L.H.)
}

Academic Editor: Auezhan Amanov

Received: 23 July 2016; Accepted: 14 September 2016; Published: 22 September 2016

\begin{abstract}
Nanomaterials, such as Graphene, h-BN nanoparticles and $\mathrm{MoS}_{2}$ nanotubes, have shown their ability in improving the tribological performance of amorphous carbon (a-C) coatings. In the current study, the effectiveness of $\mathrm{ZrO}_{2}$ nanoparticles $\left(\mathrm{ZrO}_{2}-\mathrm{NPs}\right)$ in lubricating the self-mated nonhydrogenated a-C contacts was investigated in boundary lubrication regime. The results showed that $13 \%$ less friction and $50 \%$ less wear compared to the base oil were achieved by employing $\mathrm{ZrO}_{2}-\mathrm{NPs}$ in the base oil in self-mated a-C contacts. Via analyzing the $\mathrm{ZrO}_{2}-\mathrm{NPs}$ and the worn a-C surface after tests, it was found that the improved lubrication by $\mathrm{ZrO}_{2}-\mathrm{NPs}$ was based on "polishing effects", which is a new phenomenon observed between a-C and nanoparticles. Under the "polishing effect", micro-plateaus with extremely smooth surface and uniform height were produced on the analyzed a-C surface. The resulting topography of the a-C coating is suitable for $\mathrm{ZrO}_{2}-\mathrm{NPs}$ to act as nano-bearings between rubbing surfaces. Especially, the $\mathrm{ZrO}_{2}-\mathrm{NPs}$ exhibited excellent mechanical and chemical stability, even under the severe service condition, suggesting that the combination of nonhydrogenated a-C coating with $\mathrm{ZrO}_{2}-\mathrm{NPs}$ is an effective, long lasting and environment-friendly lubrication solution.
\end{abstract}

Keywords: amorphous carbon coating; $\mathrm{ZrO}_{2}$ nanoparticles; friction coefficient; wear; polishing effect

\section{Introduction}

Nowadays, amorphous carbon (a-C) coatings, such as diamond-like carbon (DLC) coatings, have been widely applied in moving mechanical assemblies to improve the energy efficiency and avoid unwanted material wear [1-3]. To further enhance the performance of a-C coatings in oil lubricated condition, investigations into the synergetic lubrication between a-Cs and lubricating oils or additives have been extensively conducted for the past decades. However, it was found that most of the successful oil additives (such as ZDDP and MoDTC) that were tailored for metallic surface were less effective for a-Cs due to low reactivity of a-C with those chemically based additives [4-10].

Recently, researches regarding nanoparticles used as lubricating additive for a- $C$ coatings have been extensively conducted, and the results showed that nanoparticles could significantly improve the tribological performances of a-C contacts [11-19]. In traditional metallic friction pairs, the protective tribofilm formed by deposited nanoparticles is the essential tribological mechanism for most of the existing nano-additives (such as $\mathrm{Ag}, \mathrm{Cu}, \mathrm{MoS}_{2}, \mathrm{WS}_{2}$ and $\mathrm{ZrO}_{2}$ ) [20-28]. However, for a-C surfaces that have low adhesiveness and high hardness, the lubrication of nanoparticles may rely on other mechanisms. 
Kalin et al. [13] reported that the multi-wall $\mathrm{MoS}_{2}$ nanotubes could reduce the friction in a-C:H contacts by up to $50 \%$, and the improved performance was attributed to the ultra-thin $\mathrm{MoS}_{2}$ film formed by the exfoliated $\mathrm{MoS}_{2}$ nanosheets which strongly adhered on the a-C surfaces. A similar exfoliation-adhesion phenomenon was also observed with carbon nanotubes by Zhang et al. [18,19]. It is inferred that the high adhesion of exfoliated 2D nanosheets lies in the large van der Waals force and low bend stiffness. Meanwhile, the a-C coating, as a smooth and stiff substrate, assists the sliding between the absorbed nanosheets, resulting in a more effective friction reduction than that in steel contacts [13]. However, Zhang et al. [18] also suggested that the exfoliation of nanotubes only occur under high applied load, while under lower load, the friction reduction depended on the rolling of nanotubes. Zeng et al. observed ultralow friction in a-C/ $/ \mathrm{Si}_{3} \mathrm{~N}_{4}$ contacts with the aids of h-BN nanoparticles [15]. In their opinion, the reduced friction lies in the nano-bearing effect and the internal sliding between h-BN lattice planes. Berman et al. [29] obtained ultra-low friction in a-C:H/ $\mathrm{SiO}_{2}$ contacts with the nanoscrolls formed by diamond nanoparticles and graphene. The authors proposed that the nanoscrolls, as nano bearings, reduced contact area and constructed an incommensurate contact with a-C surface. In summary, in a-C contacts, the performances of nanoparticles mainly rely on the rolling motion and structural transformation (such as exfoliation and shearing) of nanomaterials.

However, the exfoliation of nanotubes or shearing of nanoparticles is a depletion process of additives, causing degradation in performance on long-term use. On the other hand, as an important lubrication mechanism of nano-additives, the nano-bearing effect that is based on the rolling of nanoparticles has not been received much attention, partly due to the adhesive nature of steel surfaces that are adverse to the rolling motion of nanoparticles. Recently, Alazami et al. [30] reported significant tribological improvement in steel contacts based on the nano-bearing effect of perfectly spherical carbon with ultra smooth surface.

Theoretically, due to high hardness and non-adhesiveness of a-C surface, it is easier for nanoparticles to realize the nano-bearing effect in a-C contacts. Among nanoparticles, ceramic nanoparticles are very suitable to act as nano-bearings owing to their excellent mechanical, chemical and thermal stabilities, and low toxicity and cost [31]. Therefore, the combination of a-C coating with ceramic nanoparticles should be an effective, long lasting, and environment-friendly lubrication solution for automobile engines, refrigeration compressor and rolling bearings. However, to the best of our knowledge, there is no literature focused on the subject.

In this paper, the zirconia nanoparticles $\left(\mathrm{ZrO}_{2}-\mathrm{NPs}\right)$, which exhibit extremely low adhesive interaction with a-C material (reported by Lu et al. [32]), were selected, and the tribological effects of $\mathrm{ZrO}_{2}-\mathrm{NPs}$ in a-C contacts were investigated. Quite promising results were obtained that both the friction and wear in a-C contacts were reduced by $\mathrm{ZrO}_{2}-\mathrm{NPs}$. The "polishing effect", a new phenomenon observed between a-C and nanoparticles, was reported, which is the critical mechanism behind the improved tribological performance.

\section{Experimental Section}

\subsection{Materials and Lubricants}

The disks for the experiments were made of GCr15 (AISI52100) steel having a hardness of $8.3 \mathrm{GPa}$ after heat treatment and a roughness Ra lower than $0.02 \mu \mathrm{m}$. The steel balls were commercially available, standard bearing steel (AISI52100) balls with the diameter of $6 \mathrm{~mm}$. Some of the disks and balls were directly used as self-mated steel contacts in the tribo tests, while others were coated with nonhydrogenated a-C on the UDP650 magnetron sputtering deposition system (Teer Coatings Ltd., Hartlebury, UK). Table 1 lists the process parameters for coating deposition. Figure 1a,b shows the cross-sectional morphology and surface topography of as-deposited a-C coating. The total thickness of as-deposited a-C coatings is $3 \mu \mathrm{m}$ with the roughness Ra of $5.9 \mathrm{~nm}$.

Commercially available $\mathrm{ZrO}_{2}-\mathrm{NPs}(99.99 \%, 50 \mathrm{~nm}$, Aladdin Industrial Corporation, Shanghai, China) were selected as lubricating additives. Figure 1c shows the HRTEM images of $\mathrm{ZrO}_{2}-\mathrm{NPs}$, 
showing the diameter of $\mathrm{ZrO}_{2}-\mathrm{NPs}$ is in the range of 30-60 nm. According to the well-established Hall-Petch (H-P) relationship, the hardness of $\mathrm{ZrO}_{2}-\mathrm{NPs}$ is higher than the bulk hardness of 6.5 on Mohs scale (equivalent to 9.8 GPa), even taking into account the inverse H-P relation [22]. The used base oil was the additive-free poly-alpha-olefin (PAO4) oil having the viscosity of $16.8 \mathrm{~mm}^{2} / \mathrm{s}$ and pressure-viscosity coefficient of $17.08 \mathrm{GPa}^{-1}$ at $40{ }^{\circ} \mathrm{C}$. The $\mathrm{ZrO}_{2}-\mathrm{NPs}$ were physically dispersed in the PAO oil at the concentrations of $1 \mathrm{wt} \%$ using an ultrasonic bath for 30 min before each tribo test. No surfactants or dispersant agents were added in order to eliminate their influence in the experiment results. The $\mathrm{ZrO}_{2}-\mathrm{NPs}$ dispersion could maintain stablity for $1 \mathrm{~h}$ as presented in the Supplementary Materials.

Table 1. The process parameters for coating deposition.

\begin{tabular}{cc}
\hline Item & Parameters \\
\hline Coating method & Magnetron sputtering deposition \\
\hline Carbon source & High-purity graphite \\
\hline Intermediate layer & $1 \times 10^{-3} \mathrm{~Pa}$ \\
\hline Base pressure & $\mathrm{Ar}, 16 \mathrm{sccm}, 0.12 \mathrm{~Pa}$ \\
\hline Working pressure & $-300 \mathrm{~V}: \mathrm{Cr}$ intermediate layer \\
\hline Bias Voltage & $-70 \mathrm{~V}:$ a-C layer \\
\hline \multirow{2}{*}{ Target current } & $3.0 \mathrm{~A}:$ Cr target \\
& $3.5 \mathrm{~A}: \mathrm{Graphite}$ target \\
\hline \multirow{2}{*}{ Deposition time } & $960 \mathrm{~s}: \mathrm{Cr}$ intermediate layer \\
& $18,000 \mathrm{~s}:$ a-C layer
\end{tabular}
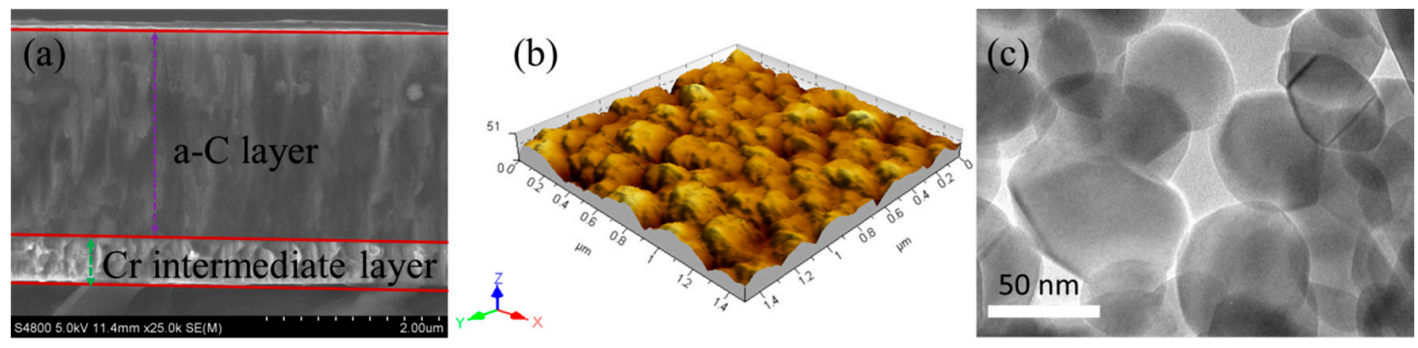

Figure 1. (a) The cross-sectional morphology; and (b) the surface topography of as-deposited a-C coating; and (c) the TEM micrographs of used $\mathrm{ZrO}_{2}-\mathrm{NPs}$.

\subsection{Tribological Evaluation}

Tribological evaluations, in which self-mated steel and a-C contacts were used, were performed on a tribometer (UMT-2, CETR, Campbell, CA, USA) with a ball-on-disk configuration. The applied load was $20 \mathrm{~N}$ resulting in an initial Hertzian contact stress about $1.1 \mathrm{GPa}$. The upper ball slides against the disk at the frequency of $5 \mathrm{~Hz}$ with the amplitude of $5 \mathrm{~mm}$ for $30 \mathrm{~min}$. The same amount of lubricants $(0.2 \mathrm{~mL})$ was spread on the disk before each test. All experiments were repeated 3-4 times to ensure statistically relevant results and the average values are presented in the Figure 2.

The theoretical minimum film thickness $\left(h_{\text {min }}\right)$ and dimensionless lambda $(\lambda)$ ratio were calculated using the Equations (1) and (2), respectively [33].

$$
\begin{gathered}
\frac{h_{\min }}{R^{\prime}}=3.63\left(\frac{U \eta_{0}}{E^{\prime} R^{\prime}}\right)^{0.68}\left(\alpha E^{\prime}\right)^{0.49}\left(\frac{W}{E^{\prime} R^{\prime 2}}\right)^{-0.073}\left(1-e^{-0.68 k}\right), \\
\lambda=\frac{h_{\min }}{\sqrt{R_{q 1}^{2}+R_{q 2}^{2}}}
\end{gathered}
$$


where $R^{\prime}$ is the reduced radius of curvature, $U$ is the entraining surface velocity, $W$ is the normal load, $E^{\prime}$ is the reduced Young's modulus, $\eta_{0}$ is the dynamic viscosity, $\alpha$ is the pressure-viscosity coefficient, $R_{q 1}$ is the surface roughness of ball, and $R_{q 2}$ is the surface roughness of disc. Under the test condition, the calculated $\lambda$ is 0.001 , suggesting that the lubrication state of friction pairs is in boundary regime $(\lambda<1)$.

\subsection{Surface Analysis}

After the tribo tests, the morphology, distribution and chemical composition of $\mathrm{ZrO}_{2}-\mathrm{NPs}$ on the worn a-C surface were analyzed with the Field Emission Scanning Electron Microscope (FESEM) (JSM-6701F, JEOL, Tokyo, Japan) and X-ray Photoelectron Spectroscopy (XPS) (PHI-5702, Physical Electronics, Al-K $\alpha$ irradiation at $29.4 \mathrm{eV}$, Chanhassen, MN, USA), respectively. Before the analysis, the worn a-C surfaces were gently rinsed with acetone to remove the lubricating oil, and special care was taken to preserve the residual $\mathrm{ZrO}_{2}-\mathrm{NPs}$ intact in the wear tracks. After analyses, the residual $\mathrm{ZrO}_{2}-\mathrm{NPs}$ were thoroughly removed by washing with acetone in ultrasonic bath for the following characterizations.

The surface profile of the wear tracks on disks was measured with an optical 3D profiler (MicroXAM, ADE Phase-Shift, Tuscon, AZ, USA). The specific wear-rate coefficient $K$ was calculated using the equation by Archard and Hirst: $K=V /(F S)$, where $V$ is the wear volume, $F$ is the applied load and $S$ is the total sliding distance [34]. The micro topography of worn a-C surfaces was analyzed via Atomic Force Microscope (AFM) (AFM-5500, Agilent Technologies, Chandler, AZ, USA). Images were taken in the tapping mode, using the commercially available type II MAC levers (nominal force constant: $2.8 \mathrm{~N} / \mathrm{m}$ ) at a driving frequency of $75 \mathrm{KHz}$ and a non-conductive silicon nitride tip (tip size: $10 \mathrm{~nm}$ ).

Raman spectroscopy (Lab JY-HR800, Horiba, 入: 532 nm, Kyoto, Japan) and XPS spectroscopy were employed to evaluate the structural changes in a-C surface after tribological tests. The mechanical properties of a-C coating after tribo tests were investigated with a nano-indenter (Nanoindentation Tester, CSM Instruments, Peseux, Switzerland, indentation depth: $100 \mathrm{~nm}$ ). The indentation hardness $(\mathrm{H})$ and elastic modulus (E) were calculated with the Oliver-Pharr model from simulated P-h curves (Poisson's ratio: 0.3).

\section{Results and Discussion}

\subsection{Tribological Results}

Figure $2 \mathrm{a}, \mathrm{b}$ presents the coefficients of friction $(\mathrm{COF})$ and the wear rates of steel/steel and a-C/a-C contacts, respectively. In steel contacts, compared with pure PAO lubricated condition, the $\mathrm{ZrO}-\mathrm{NPs}_{2}$ remarkably increase the friction and wear. However, in a-C contacts, the adding of $\mathrm{ZrO}_{2}-\mathrm{NPs}$ in PAO is very effective in friction and wear reduction. As shown in Figure 2, the COFs of a-C contacts were reduced by $13 \%$, and the wear rates were lowered by $50 \%$.
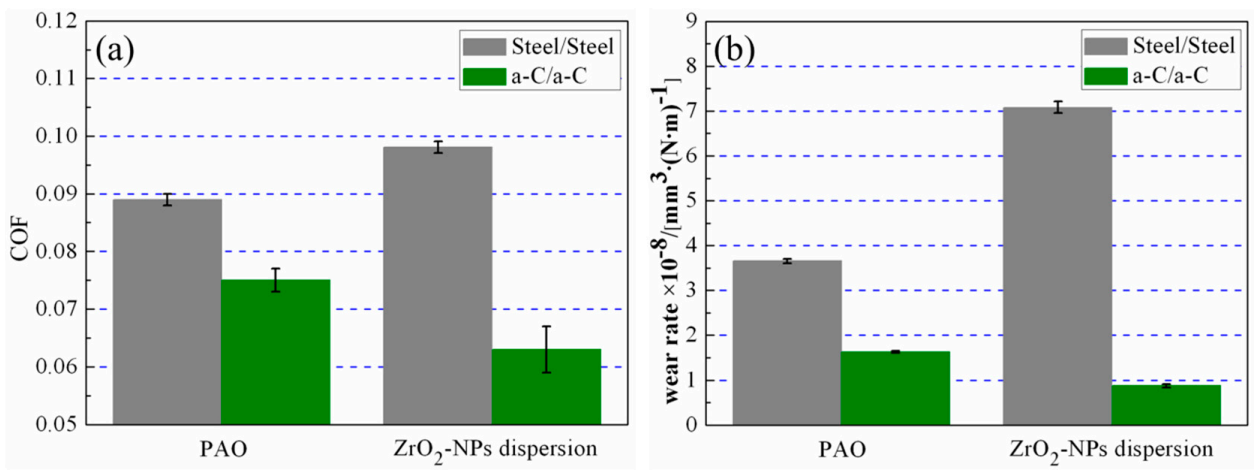

Figure 2. (a) The average COFs; and (b) wear rates of steel/steel and a-C/a-C contacts under the lubrication of pure PAO and $\mathrm{ZrO}_{2}-\mathrm{NPs}$ dispersion. 
Figure 3 shows the morphology and cross-sectional profile of the wear tracks on the a-C and steel disks, and corresponding wear scar on the slider balls. It shows that, in pristine PAO, the steel contacts exhibit typical adhesive wear indicated by the obvious large protruding peaks in the wear tracks region (Figure 3a). Lubricated with $\mathrm{ZrO}_{2}-\mathrm{NPs}$ dispersion, deep grooves could be observed on the wear track and wear scar of steel contacts, and the diameter of wear scar on steel ball is increased by $\mathrm{ZrO}_{2}-\mathrm{NPs}$ (Figure 3d), suggesting that the $\mathrm{ZrO}_{2}-\mathrm{NPs}$, acting as abrasive particles, plowed the steel surfaces during friction.

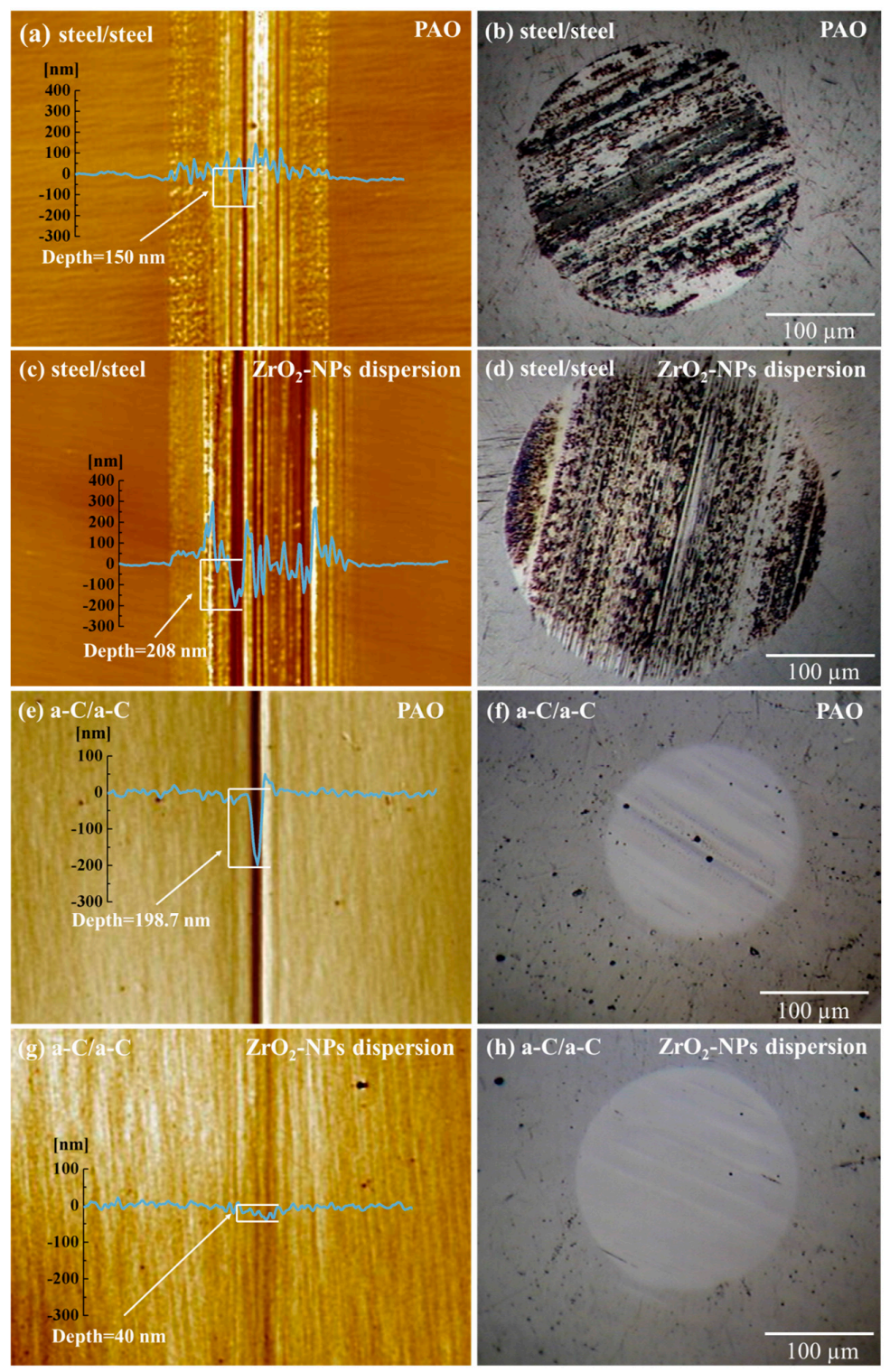

Figure 3. The morphology and cross-sectional profile of the wear tracks on: $(\mathbf{a}, \mathbf{c})$ steel; and $(\mathbf{e}, \mathbf{g})$ a-C disks. The optical micrographs of the wear scar on: (b,d) steel balls; and (f,h) a-C coated balls.

In a-C contacts, quite different effects were observed. Under the lubrication of pristine PAO oil, abrasive wear took place in a-C contacts, producing deep grooves on the surfaces of a-C disk and a-C coated slider ball (Figure 3e,f). Introducing $\mathrm{ZrO}_{2}-\mathrm{NPs}$ into PAO oil could remarkably alleviate the abrasive wear, which is evidenced by the shallower grooves on the wear track and the smooth surface of wear scar (Figure 3g,h). By comparing the tribological effects of $\mathrm{ZrO}_{2}-\mathrm{NPs}_{\text {in }}$ steel and a-C contacts, it could be concluded that the $\mathrm{ZrO}_{2}-\mathrm{NPs}$ exhibit remarkable synergetic lubricating effects with analyzed nonhydrogenated a-C coating, and the following section will focus on the synergetic effect between them, and elucidating its mechanisms. 


\subsection{The Synergetic Lubricating Mechanism between a-C and $\mathrm{ZrO}_{2}-\mathrm{NPS}$}

\subsubsection{The Characterizations of the Residual $\mathrm{ZrO}_{2}-\mathrm{NPs}$ on the Worn a-C Surface}

Through the pretreatment methods as stated in Section 2.3, it is possible to investigate the morphology and distribution of the residual $\mathrm{ZrO}_{2}-\mathrm{NPs}$ on the worn a-C surfaces after tribo tests, which is helpful to understand the role of $\mathrm{ZrO}_{2}-\mathrm{NPs}$ in advancing the tribological performances of a-C contacts. Figure 4 shows the FESEM images of the residual $\mathrm{ZrO}_{2}-\mathrm{NPs}$ on the wear track on a-C disk. The $\mathrm{ZrO}_{2}-\mathrm{NPs}$ are evenly distributed on the worn track (Figure $4 \mathrm{a}$ ), and most of the $\mathrm{ZrO}_{2}-\mathrm{NPs}$ maintain their initial spherical morphology after being tested under boundary lubrication condition (Figure $4 \mathrm{~b}$ ). The distribution of $\mathrm{ZrO}_{2}-\mathrm{NPs}$ (in Figure 4c) shows that the $\mathrm{ZrO}_{2}-\mathrm{NPs}$ are preferentially distributed at the boundaries of micro-regions on a-C surfaces. Referring to the topography of as-deposited a-C coating in Figure 1b, the micro-regions correspond to the micro-bumps on a-C and the boundaries are the valleys between them. Thus, it reveals that the $\mathrm{ZrO}_{2}-\mathrm{NPs}$ could fill the nano-scale valleys on a-C surfaces.
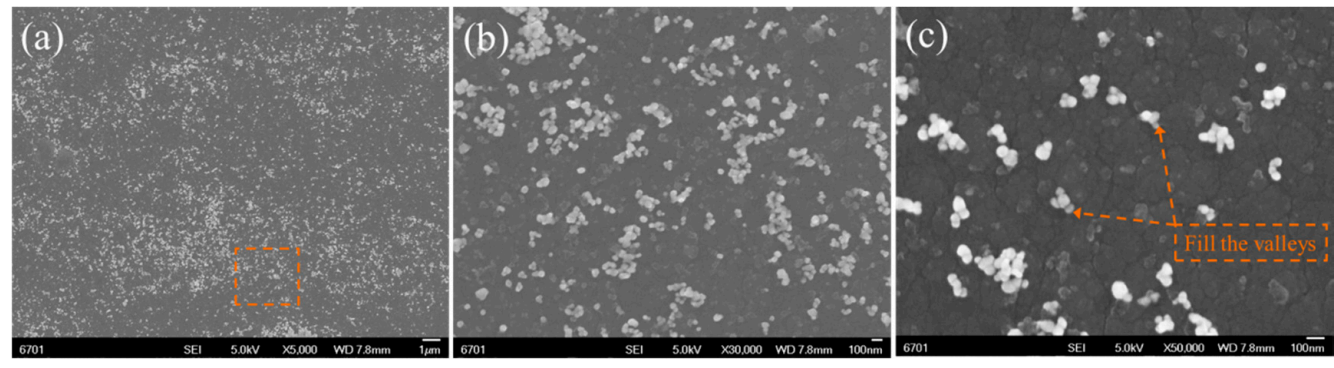

Figure 4. (a) FESEM images of the residual $\mathrm{ZrO}_{2}-\mathrm{NPs}$ on the worn a-C surfaces after friction; (b) magnified details of the region marked in Figure $4 \mathrm{a}$; and (c) the distribution state of $\mathrm{ZrO}_{2}-\mathrm{NPs}_{\text {. }}$

Not only the morphology but also the compositional properties of $\mathrm{ZrO}_{2}-\mathrm{NPs}$ were preserved during tribo tests. In Figure 5, the XPS spectra of the residual $\mathrm{ZrO}_{2}-\mathrm{NPs}$ exhibit two spin-orbit components, the $3 \mathrm{~d}_{5 / 2}$ at $183.3 \mathrm{eV}$ and $3 \mathrm{~d}_{3 / 2}$ at $185.7 \mathrm{eV}$, which correspond to the $\mathrm{Zr}^{4+}$ in oxidation state $[35,36]$. Thus, no chemical reaction occurred between $\mathrm{ZrO}_{2}-\mathrm{NPs}$ and a-C coating during friction, indicating that the improved tribological performance of a-C contacts by $\mathrm{ZrO}_{2}-\mathrm{NPs}$ should be ascribed to physically based effects such as the nano-bearing or valleys-filling effects. To further confirm the above deduction, worn a-C surfaces were analyzed in detail after the residual $\mathrm{ZrO}_{2}-\mathrm{NPs}$ were thoroughly removed.

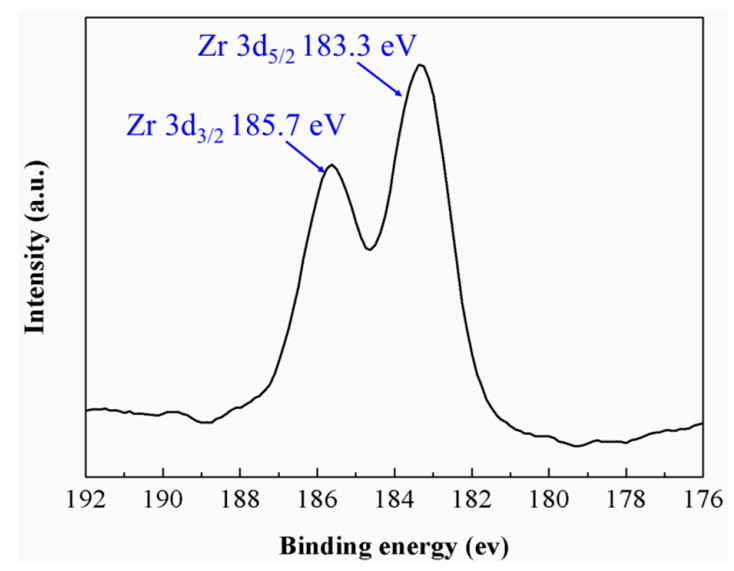

Figure 5. The XPS spectra of the residual $\mathrm{ZrO}_{2}-\mathrm{NPs}$ on the worn a-C surface. 


\subsubsection{The Characterizations of the Worn a-C Surfaces}

Figure 6 presents the FESEM images of worn a-C surfaces after tribo tests. With pure PAO oil, the worn a-C surface shows compacted micro-regions with the diameter range around $100 \sim 300 \mathrm{~nm}$. In comparison, with $\mathrm{ZrO}_{2}-\mathrm{NPs}$ dispersion, a special damage appearance was produced. As shown in Figure $6 \mathrm{~b}$, numerous white spots can be found on the worn a-C surface, and the white spots are located on the center of the micro-regions.

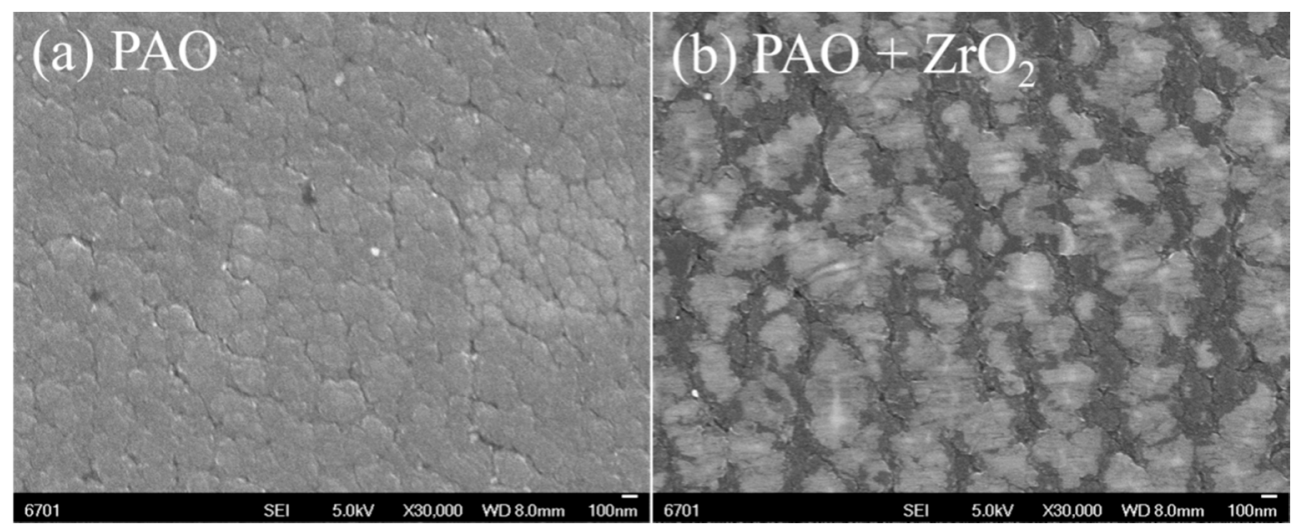

Figure 6. The FESEM images of worn a-C surfaces under the lubrication of: (a) pristine PAO oil; and (b) $\mathrm{ZrO}_{2}-\mathrm{NPs}$ dispersion.

The topography of the white spot in Figure $6 \mathrm{~b}$ was analyzed via AFM. Results show that the white spots have the plateau-like topography, and the sliding traces of $\mathrm{ZrO}_{2}-\mathrm{NPs}$ can be observed on the top surfaces of plateaus (Figure 7). Clearly, the resulted plateau-like topography on analyzed a-C surface should be caused by the polishing from the $\mathrm{ZrO}_{2}$-NPs. It is noteworthy that such "polishing effect" could only be observed with $\mathrm{ZrO}_{2}$-NPs in current study. As presented in the Supplementary Materials, when we investigated the tribological effects of $W$ nanoparticles that contain particles with submicron and micron size (Figure S1), micro-scratches, instead of micro-plateaus, were produced on the analyzed a-C surface (Figures S2 and S3), suggesting that the "polishing effect" between a-C and the third-body particles is highly dependent on size and size distribution of the particles.

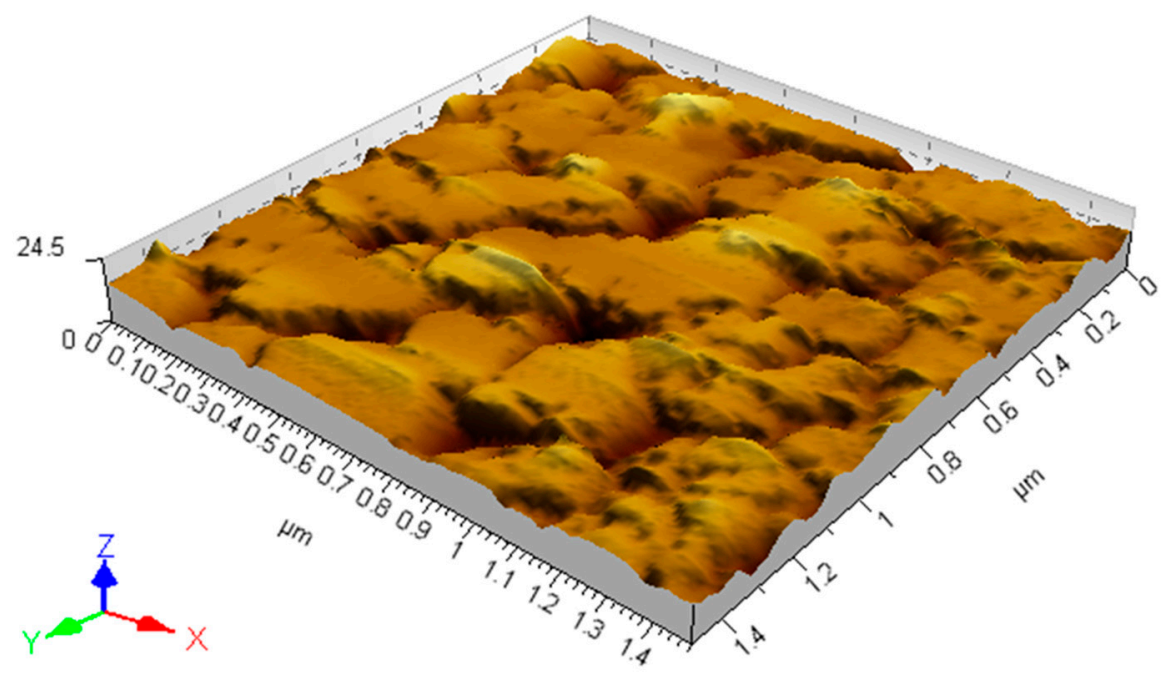

Figure 7. The topography of worn a-C surface under the lubrication of $\mathrm{ZrO}_{2}-\mathrm{NPs}$ dispersion.

Figure 8 presents the topography and corresponding roughness parameters of as-deposited a-C coating and the worn a-C surface under the lubrication of pure $\mathrm{PAO}$ and $\mathrm{ZrO}_{2}-\mathrm{NPs}$ dispersion. 
As shown in Figure 8c, under the "polishing effect" of $\mathrm{ZrO}_{2}-\mathrm{NPs}$, the micro-bumps on a-C surface transformed into micro-plateaus with significantly decreased $R a$ and $R q$. The $R z$ is decreased to $23 \mathrm{~nm}$, which is smaller than the diameter of $\mathrm{ZrO}_{2}$-NPs. In addition, the Rsk (Skewness of the profile height distribution) becomes more negative, indicating that the asperities were preferentially removed during polishing process. The $R k u$ (Kurtosis of the profile height distribution) increases from 3.2 to 4.5 , meaning that the height distribution become narrow, i.e., the height of micro-plateaus is very uniform. In comparison, under the lubrication of pure PAO (Figure $8 b$ ), although the $R a, R q, R z$ and $R s k$ decrease to some extent, the $R k u$ only changed a little and is very close to 3 , indicating that, under the lubrication of pure PAO, the profile height distribution of the worn a-C surface is in Gaussian distribution, which is similar to the as-deposited a-C coating.
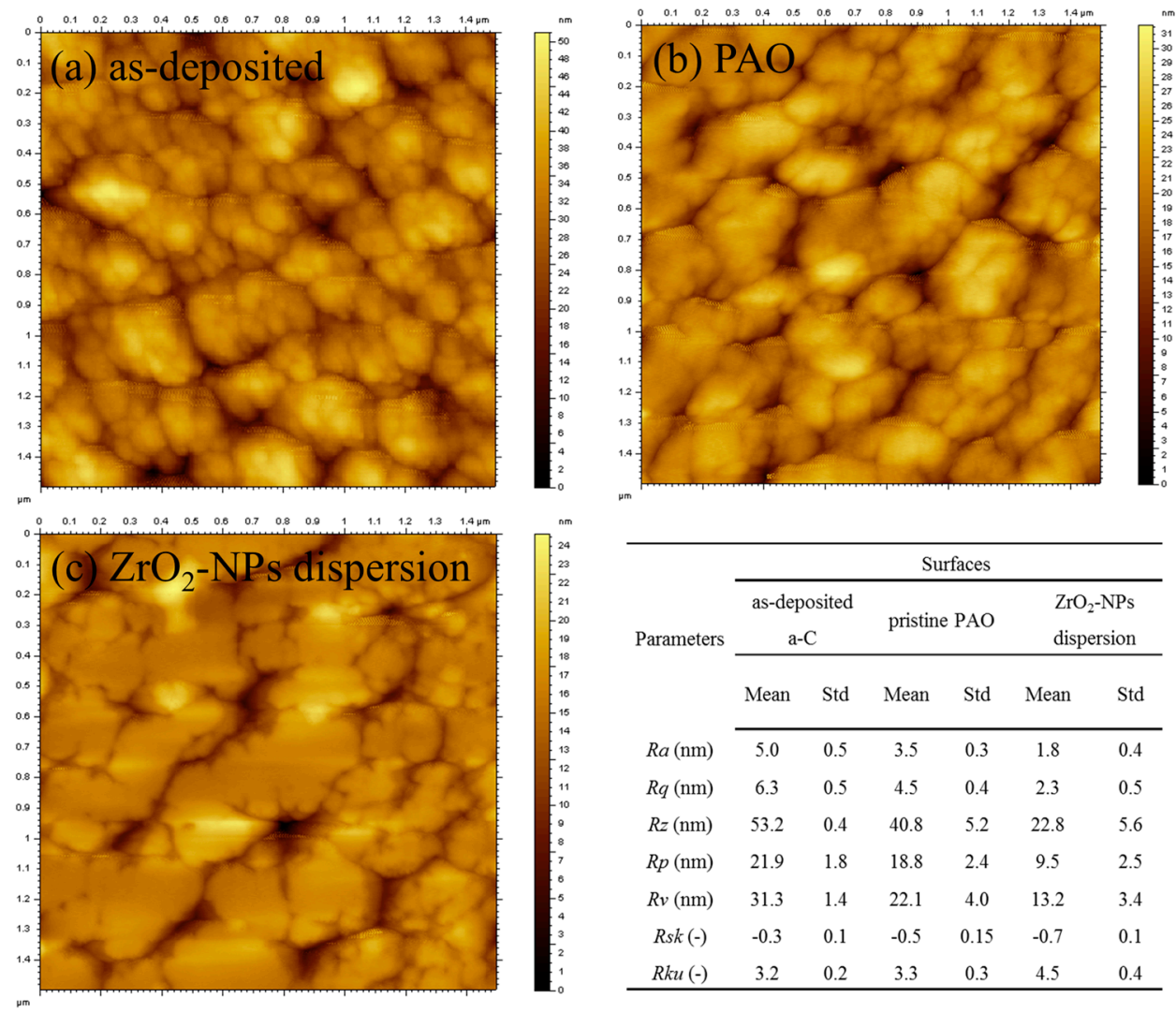

Figure 8. The topography and roughness parameters of: (a) as-deposited a-C coating; and the worn a-C surfaces under the lubrication of: (b) pure PAO; and (c) $\mathrm{ZrO}_{2}-\mathrm{NPs}$ dispersion.

The XPS were employed to investigate the changes of surface chemical composition of a-C during friction. Figure 9 shows the C1s peak in the XPS spectra obtained from the as-deposited and the worn a-C surface that was lubricated with $\mathrm{ZrO}_{2}-\mathrm{NPs}$ dispersion. The $\mathrm{C} 1 \mathrm{~s}$ peaks were fitted by $(80 \%$ Gaussian $+20 \%$ Lorentzian) function. The full width at half maximum (FWHM) of the fitted peaks was set at $1.60 \mathrm{eV}$, and four components centered at $284.5 \mathrm{eV}$ (Csp2), $285.2 \mathrm{eV}$ (Csp3), $286.7 \mathrm{eV}$ $(\mathrm{C}-\mathrm{O})$, and $288.7 \mathrm{eV}(\mathrm{C}=\mathrm{O})$ were obtained according to the references [37-39]. The areas under the Csp2 and Csp3 peaks were used to determine the Csp3/Csp2 ratio in a-C. As shown in Figure 9, compared with as-deposited a-C, the $\mathrm{Csp} 3 / \mathrm{Csp} 2$ ratio of worn a-C surface shows no obvious changes after tribo tests, indicating that the $\mathrm{ZrO}_{2}$-NPs did not affect the surface chemical composition of a-C during friction. 

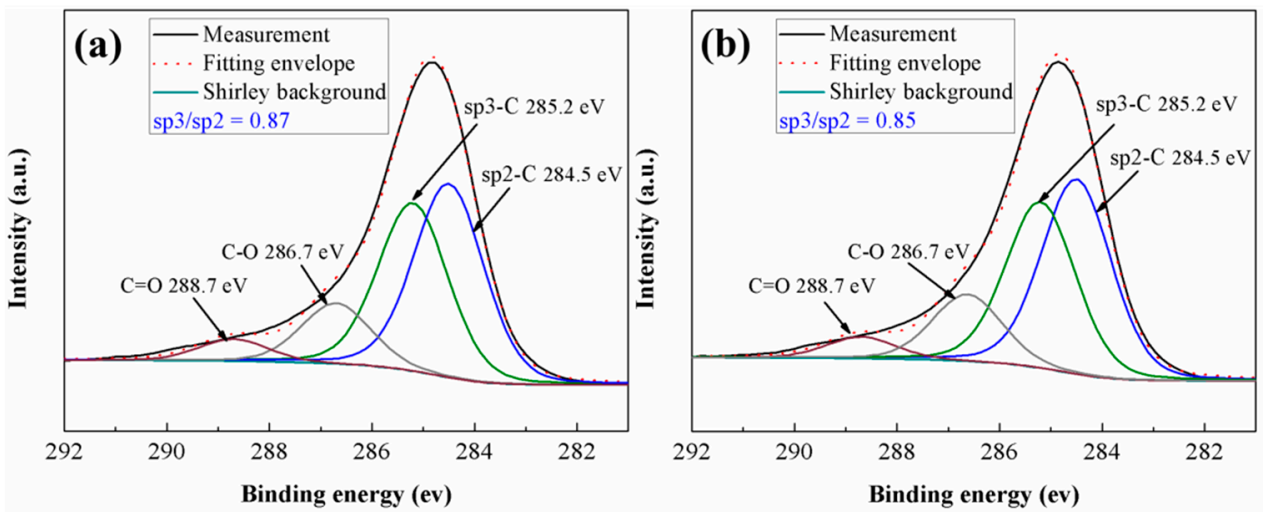

Figure 9. The fitting results of the C1s peak in XPS spectra of: (a) as-deposited a-C; and (b) the worn a-C surface under the lubrication of $\mathrm{ZrO}_{2}-\mathrm{NPs}$ dispersion.

Then, the bonding structure, especially the configuration of sp2 hybridized carbon in a-C, were investigated using Raman spectroscopy. Figure 10 shows the Raman spectra obtained from the as-deposited a-C and the worn a-C surface. All spectra show the similar broad peak between 1100 and $1750 \mathrm{~cm}^{-1}$, which is typical for a-C, suggesting the a-C coating preserved the amorphous structure during friction. The spectra were deconvoluted by the BWF + Lorentzian pair into two main Raman bands, one located at $1550 \mathrm{~cm}^{-1}$ (G band), and the other at $1360 \mathrm{~cm}^{-1}$ (D band). The program FITYK was applied for peak fitting using the Levenberg-Marquard algorithm for nonlinear least-square optimization. The fitting results of $G$ peak position $\left(G_{\max }\right)$ and the $I_{D} / I_{G}$ ratio (peak height ratio) from the Raman spectra are inserted in Figure 10.
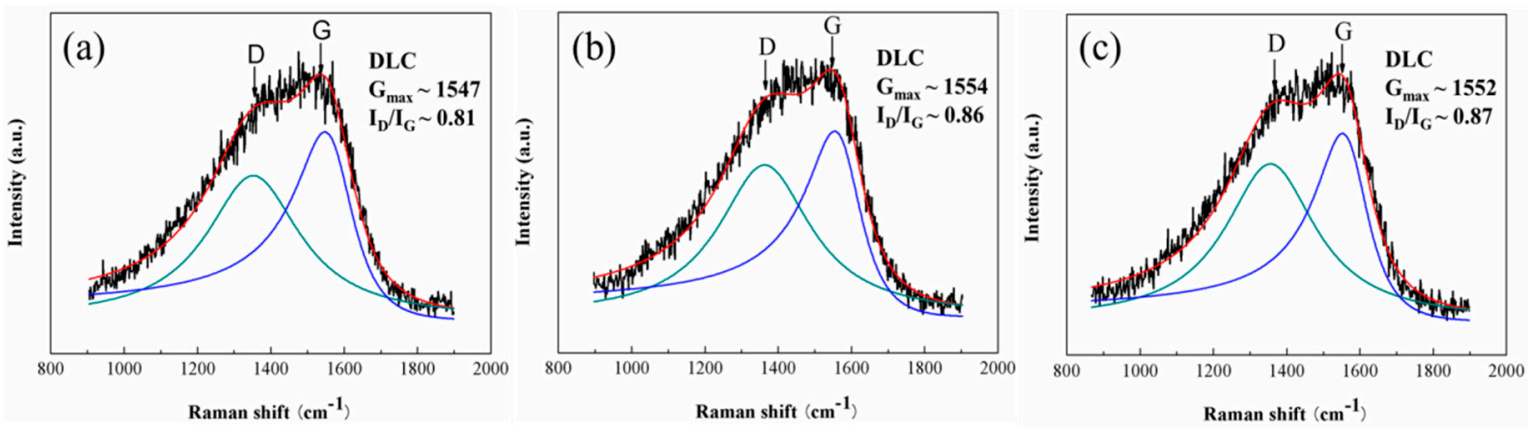

Figure 10. The Raman spectra of: (a) as-deposited a-C; and the wear tracks on a-C under the lubrication of: (b) pure PAO; and (c) $\mathrm{ZrO}_{2}-\mathrm{NPs}$ dispersion. The insets show the fitting results of $\mathrm{G}$ peak position $\left(\mathrm{G}_{\max }\right)$ and the $\mathrm{I}_{\mathrm{D}} / \mathrm{I}_{\mathrm{G}}$ ratio (height ratio).

The fitting results show that the $G$ peaks shift to higher frequencies with increased $I_{D} / I_{G}$ ratios after being tested in both lubricants. According to the "Three Stage Model" proposed by Ferrari et al. [40], the microstructure of analyzed a-C coating belong to the Stage 2, in which the G peak position is related with the ordering of bond-angle and bond-bending of Csp2 in rings, while $I_{D} / I_{G}$ ratios is dependent on the number of ordered aromatic rings. Therefore, after the tribo tests, the blue shift of $\mathrm{G}_{\max }$ with the increased $\mathrm{I}_{\mathrm{D}} / \mathrm{I}_{\mathrm{G}}$ ratio indicate that the Csp2 in a-C surface became more ordered during friction.

During friction, the ordering of Csp2 in a-C was triggered by the frictional heat, and the high contact stress exerted by the abrasive particles could promote the transformation [41]. However, as suggested by the fitting results, the $\mathrm{ZrO}_{2}-\mathrm{NPs}$ did not promote the transformation during friction, possibly due to the nano-scale size of the $\mathrm{ZrO}_{2}-\mathrm{NPs}$, which is even smaller than the asperities on the 
analyzed a-C coating, and the uniform size distribution of $\mathrm{ZrO}_{2}-\mathrm{NPs}$, which ensure the load is evenly supported by the nanoparticles in the contact region.

Via nano-indentation tests, it is found that the worn a-C surfaces under the lubrication of $\mathrm{ZrO}_{2}$-NPs dispersion and pure PAO exhibit similar indentation-recovery behavior (Figure 11). The extracted coating hardness $(\mathrm{H})$ and elastic modulus $(\mathrm{E})$, which were obtained by averaging the results from four parallel tests (see more details in Supplementary Materials), are similar for two test conditions (Figure 11, inset). Additionally, it is interesting to note that the $\mathrm{H}$ and $\mathrm{E}$ obtained from the worn a-C surfaces are slightly higher than those obtained from the as-deposited a-C.

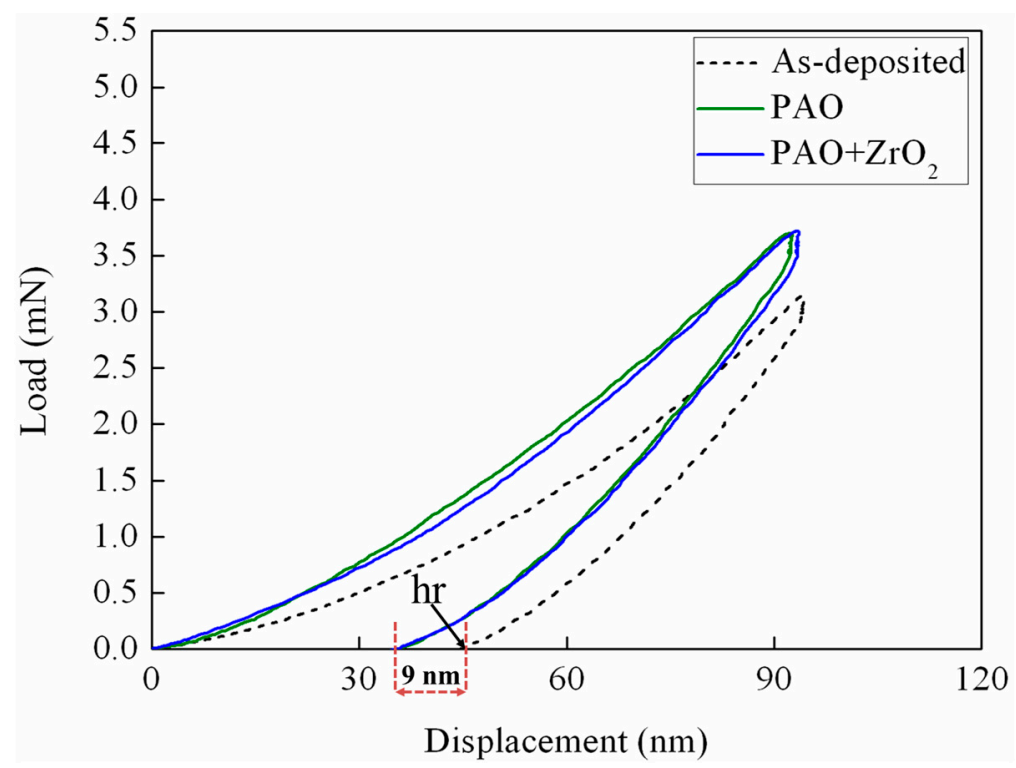

Figure 11. The load-displacement curves obtained from the as-deposited a-C and from the wear tracks on a-C under the lubrication of pure PAO and $\mathrm{ZrO}_{2}-\mathrm{NPs}$ dispersion. The inset shows the average results of hardness $(\mathrm{H})$ and elastic modulus (E) from four parallel tests (Figure S5), hr: residual depth after completed unloading.

The phenomenon should be related with the non-uniform cross-sectional structure of a-C coating. As reported by Ferrari et al., the magnetron sputtered a-C coating (thickness: $360 \mathrm{~nm}$ ) consists of a dense bulk layer $\left(1.7 \mathrm{~g} / \mathrm{cm}^{3}\right)$ and a less dense surface layer $\left(1.15 \mathrm{~g} / \mathrm{cm}^{3}\right.$, thickness: $\left.5 \mathrm{~nm}\right)$, which is originated from the subplantation mechanism during deposition [42]. The difference in $\mathrm{hr}(9 \mathrm{~nm})$ between as-deposited a-C and the worn a-C in Figure 11 implies the existence of the surface layer in analyzed a-C coating. In addition, a high coating hardness is necessary to realize the beneficial effects of $\mathrm{ZrO}_{2}$-NPs. As presented in the Supplementary Materials, for the $\mathrm{Cr}$-doped a-C with the hardness of 9.9 GPa, the $\mathrm{ZrO}_{2}-\mathrm{NPs}$ dispersion cannot reduce the friction, but can significantly increase the wear rate. Thus, the $\mathrm{ZrO}_{2}-\mathrm{NPs}$, which have hardness higher than $10 \mathrm{GPa}$, may be not suitable for the a-C coatings with the hardness below $10 \mathrm{GPa}$.

\subsection{The Tribological Mechanism of $\mathrm{ZrO}_{2}-\mathrm{NPs}$ in a-C Contacts}

As presented above, the $\mathrm{ZrO}_{2}$-NPs exhibit adverse tribological effects in steel contacts, but effectively reduce the friction and wear in a-C contacts. Due to the "polishing effect" of $\mathrm{ZrO}_{2}-\mathrm{NPs}$ during friction, a special topography was obtained on a-C surface with no influences in the compositional and mechanical properties of analyzed a-C coating. However, the topography of contact surfaces will significantly affect the distribution and sliding/rolling of the nanoparticles between them. Actually, the bumpy surface of as-deposited a-C coating is not favorable for the rolling of $\mathrm{ZrO}_{2}$-NPs. However, after polished by $\mathrm{ZrO}_{2}-\mathrm{NPs}$, the micro-bumps transformed into 
micro-plateaus with extremely smooth surface and uniform height, which is suitable for $\mathrm{ZrO}_{2}-\mathrm{NPs}$ to act as nano-bearings to reduce the friction and wear.

By specially focusing on the morphology evolution of a-C surface under the lubrication of $\mathrm{ZrO}_{2}-\mathrm{NPs}$ dispersion, it is found that the a-C surface has been finely polished by $\mathrm{ZrO}_{2}-\mathrm{NPs}$ within 5 min (1500 cycles) after the sliding started (Figure 12c). The reason why the a-C surface could be polished in such a short time may be because the analyzed a-C coating contains a less dense surface layer, as has been discussed above.

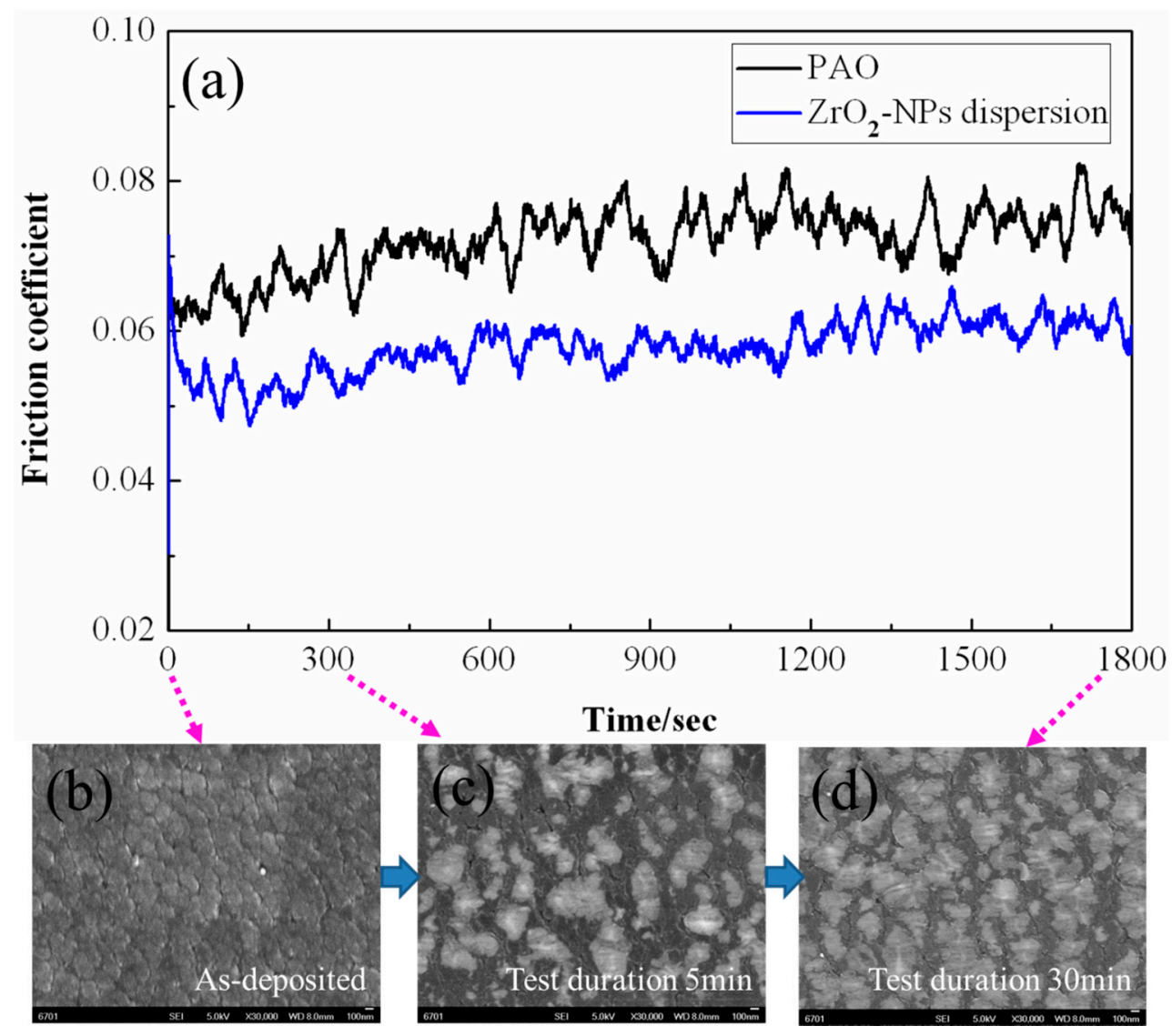

Figure 12. (a) The variation of COF of a-C contacts with respect to sliding time. The FESEM images of: (b) the as-deposited a-C surface; and the worn a-C surface under the lubrication of $\mathrm{ZrO}_{2}-\mathrm{NPs}$ dispersion for: (c) $5 \mathrm{~min}$; and (d) $30 \mathrm{~min}$.

Figure 13a shows the $\mathrm{COF}$ variation of a-C contacts during the first $1 \mathrm{~min}$ of tribo tests. In the initial stage, the $\mathrm{COF}$ of $\mathrm{ZrO}_{2}-\mathrm{NPs}$ lubricated a-C contacts is higher the $\mathrm{COF}$ of pure $\mathrm{PAO}$ lubricated condition, but is close to the COF of PAO lubricated $\mathrm{ZrO}_{2}$ /a-C contacts under the same test condition (Figure 13b). It is speculated that the high initial $\mathrm{COF}$ of $\mathrm{ZrO}_{2}-\mathrm{NPs}$ dispersion should be related with the "polishing" process, during which most of the $\mathrm{ZrO}_{2}-\mathrm{NPs}$ are sliding on the a-C surface. At the initial running-in stage, the $\mathrm{ZrO}_{2}-\mathrm{NPs}$ could not roll freely on the bumpy a-C surface. Under the shearing action, the motion of $\mathrm{ZrO}_{2}-\mathrm{NPs}$ is blocked by the micro-bumps due to their similar dimension. The $\mathrm{ZrO}_{2}-\mathrm{NPs}$ will exert a high stress on the micro-bumps, and then polish the surface of the micro-bumps. This also explains the reason why the "polishing effect" on analyzed a-C coatings was observed with $\mathrm{ZrO}_{2}-\mathrm{NPs}_{\text {, }}$ and could not be observed with the particles of micron size (see Supplementary Materials).

Once the a-C surface was polished and the micro-plateaus were formed, the $\mathrm{ZrO}_{2}-\mathrm{NPs}$ between sliding surfaces should be in rolling state, because the siding of $\mathrm{ZrO}_{2}-\mathrm{NPs}$ could not lower the friction of a-C contacts $\left(\mathrm{COF}_{\mathrm{ZrO}_{2} / \mathrm{a}-\mathrm{C}}>\mathrm{COF}_{\mathrm{a}-\mathrm{C} / \mathrm{a}-\mathrm{C}}\right)$. However, if the $\mathrm{ZrO}_{2}-\mathrm{NPs}$ are in pure rolling state, the $\mathrm{COF}$ should be much lower than the presented results. Therefore, it is inferred that the $\mathrm{ZrO}_{2}-\mathrm{NPs}$ 
were in a rolling-sliding state with high sliding ratio. Additionally, because the $\mathrm{ZrO}_{2}-\mathrm{NPs}$ can fill the valleys between the micro-plateaus (Figure 4c), the real contact area between contacted a-C surface is increased, which lowers the contact stress and reduces the wear.
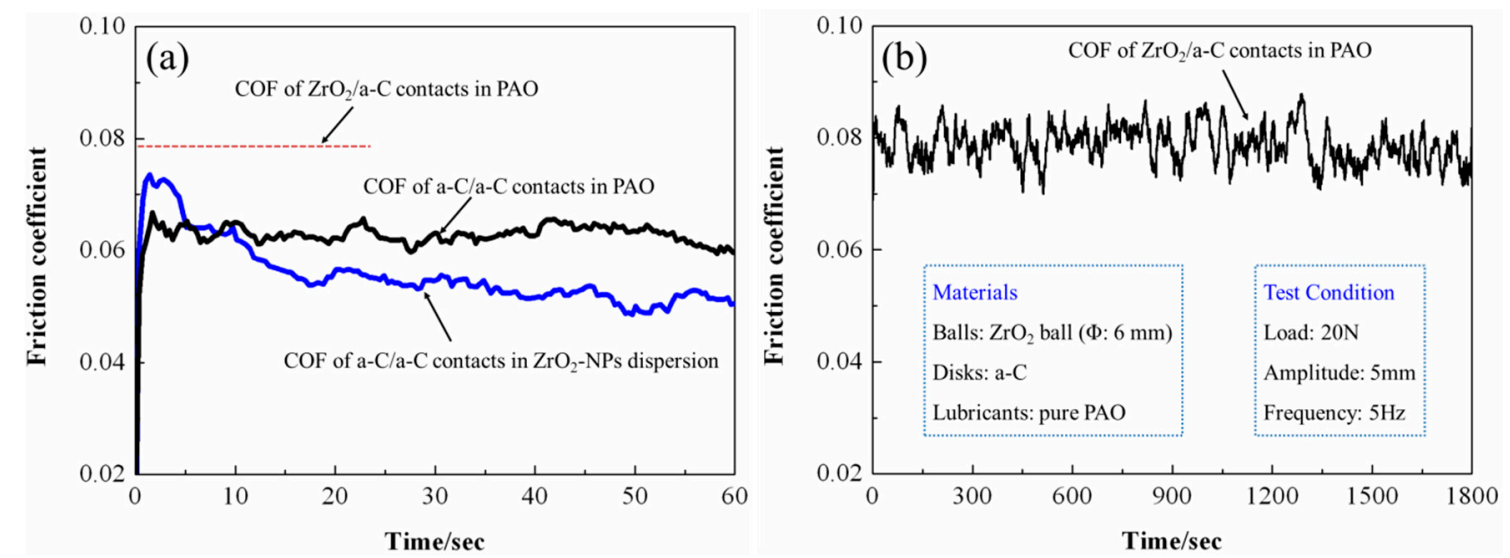

Figure 13. (a) The COF variation of a-C contacts during the initial stage under the lubrication of pure $\mathrm{PAO}$ and $\mathrm{ZrO}_{2}$-NPs dispersion; (b) The COF variation of $\mathrm{ZrO}_{2} / \mathrm{a}-\mathrm{C}$ contacts under the lubrication of pure $\mathrm{PAO}$, the inset presents the test conditions.

Therefore, although the improved tribological performances of a-C coatings by $\mathrm{ZrO}_{2}-\mathrm{NPs}$ can be ascribed to the nano-bearing effect, which lowers the friction, and the valleys-filling effect, which reduces the wear, the "polishing effect" is critical for the acting of these mechanism. It needs to be pointed out that the "polishing effect" between nanoparticles and a-C highly depends on the diameter of nanoparticles and the mechanical properties of a-C coatings. So the selection of nanoparticles should be based on the topography and mechanical properties of used a-C coating. Otherwise, severe scratch damages and high wear will be resulted, as what is presented in the Supplementary Materials and the previous studies [43].

In addition, the "polishing effect" is also dependent on the cross-sectional structure of a-C coatings. Since other kinds of a-Cs, such as ta-C, a-C:H and ta-C:H, have quite different cross-sectional structure (especially the thickness of surface layer) from the analyzed a-C coating in current study [43], whether these a-C coatings can be "polished" by $\mathrm{ZrO}_{2}-\mathrm{NPs}$ is still unknown. Thus, the beneficial effects of $\mathrm{ZrO}_{2}$-NPs observed in current study are only restricted to the magnetron sputtered a-C coatings which have a significant surface layer structure and the high bulk hardness above $15 \mathrm{GPa}$. In the future, it is necessary to conduct a systematical investigation into the tribological effects of $\mathrm{ZrO}_{2}-\mathrm{NPs}$ on other kinds of a-C coatings to elucidate the applicability of $\mathrm{ZrO}_{2}-\mathrm{NPs}$ in a-C friction pairs.

\section{Conclusions}

The addition of $\mathrm{ZrO}_{2}-\mathrm{NPs}$ to PAO oil significantly improved the tribological performance of self-mated a-C contacts in boundary lubrication regime. At the concentration of $1 \mathrm{wt} \%$, the friction of a-C contact pairs was lowered by $13 \%$, and the wear was reduced by $50 \%$. The "polishing effect", which is the critical mechanism behind the improved tribological performance, was reported. Under the polishing effect of $\mathrm{ZrO}_{2}-\mathrm{NPs}$, micro-plateaus with extremely smooth surface and uniform height were produced on the analyzed a-C surface. The resulted topography of a-C coating was suitable for $\mathrm{ZrO}_{2}-\mathrm{NPs}$ to act as nano-scale ball bearings to lower the friction and wear by rolling and sliding.

It was found that the "polishing effect" between a-C and nanoparticles highly depends on the diameter of nanoparticles, as well as the mechanical properties and cross-sectional structure of a-C coatings. Thus, the beneficial effects of $\mathrm{ZrO}_{2}-\mathrm{NPs}$ observed in the current study are only restricted to the magnetron sputtered nonhydrogenated a-C coatings that have a significant surface layer and bulk hardness above $15 \mathrm{GPa}$. In the future, it is necessary to conduct a systematical investigation on other 
kinds of a-C coatings to elucidate the applicability of $\mathrm{ZrO}_{2}-\mathrm{NPs}$ to be used as lubricating additives for $\mathrm{a}-\mathrm{C}$ coated friction pairs.

Supplementary Materials: The following are available online at www.mdpi.com/1996-1944/9/10/795/s1. Figure S1: FESEM images of the residual W-NPs on the worn a-C surfaces after tribo tests; (b) show the magnified details of the region marked in the Figure S1a; Figure S2: The FESEM images of the worn a-C surfaces when tested with W-NPs. $(b, c)$ show the details of the region marked in Figure S2a; Figure S3: The topography and (b) line profile from the white line of the worn a-C surfaces when tested with W-NPs; (c) The wear rates of a-C lubricated with pristine $\mathrm{PAO}$ and $\mathrm{PAO}$ with $\mathrm{W}-\mathrm{NPs}$ and $\mathrm{ZrO}_{2}-\mathrm{NPs}$; Figure S4: The load-displacement curves in the nano-indentation tests performed on the (a) as-deposited a-C surface and the worn a-C surface when lubricated with (b) pristine PAO oil and (c) PAO with $\mathrm{ZrO}_{2}-\mathrm{NPs}$, respectively; Figure S5: (a) The nano-indentation results of $\mathrm{Cr}$ doped a-C coating; (b) The $\mathrm{COF}$ of $\mathrm{Cr}$ doped a-C contacts under the lubrication of pure $\mathrm{PAO}$ and $\mathrm{ZrO}_{2}-\mathrm{NPs}$ dispersion; (c) The wear rates of a-C and $\mathrm{Cr}$-doped a-C under the lubrication of pure $\mathrm{PAO}$ and $\mathrm{ZrO}_{2}-\mathrm{NPs}$ dispersion; Figure S6: Digital images of dispersion of $\mathrm{ZrO}_{2}-\mathrm{NPs}$ in $\mathrm{PAO}$ oil. The time for each picture is noted on the respective picture: (a) the as-prepared $\mathrm{ZrO}_{2}$-NPs dispersion; and the dispersion after standing for (b) $1 \mathrm{~h}$; (c) $2 \mathrm{~h}$; (d) $3 \mathrm{~h}$ and (e) $12 \mathrm{~h}$. Concentration of $\mathrm{ZrO}_{2}$-NPs: $1 \mathrm{wt} \%$.

Acknowledgments: The research is financially supported by the National Natural Science Foundation of China (Grant Nos. 51575506 and 51505462) and Applied Basic Research Project of Qingdao: Youth Program (Grant No. 14-2-4-85-JCH).

Author Contributions: J.Z.T. and Q.D. conceived and designed the experiments; J.Z.T., S.W.Z. and G.Z.W. performed the experiments; J.Z.T., Q.D. and L.T.H. analyzed the data; and J.Z.T., Q.D. and L.T.H. wrote the paper.

Conflicts of Interest: The authors declare no conflict of interest. The founding sponsors had no role in the design of the study; in the collection, analyses, or interpretation of data; in the writing of the manuscript, and in the decision to publish the results.

\section{Abbreviations}

The following abbreviations are used in this manuscript:

$\begin{array}{ll}\mathrm{a}-\mathrm{C} & \text { Amorphous carbon } \\ \mathrm{DLC} & \text { Diamond-like carbon } \\ \mathrm{ZrO} \text {-NPs } & \text { Nanoparticles of zirconia } \\ \mathrm{Std} & \text { Standard deviation } \\ \mathrm{Ra} & \text { Arithmetic mean deviation of the profile } \\ \mathrm{Rq} & \text { Root mean square deviation of the profile } \\ \mathrm{Rz} & \text { Maximum height of the profile } \\ \mathrm{Rp} & \text { Maximum profile peak height } \\ \mathrm{Rv} & \text { Maximum profile valley depth } \\ \mathrm{Rsk} & \text { Skewness of the profile height distribution } \\ \mathrm{Rku} & \text { Kurtosis of the profile height distribution } \\ \mathrm{hr} & \text { Residual depth after completed unloading }\end{array}$

\section{References}

1. Kalin, M.; Velkavrh, I.; Vižintin, J.; Ožbolt, L. Review of boundary lubrication mechanisms of DLC coatings used in mechanical applications. Meccanica 2008, 43, 623-637. [CrossRef]

2. Kano, M. DLC coating technology applied to sliding parts of automotive engine. New Diam. Front. Carbon Coat. 2006, 16, 201-210.

3. Erdemir, A. Review of engineered tribological interfaces for improved boundary lubrication. Tribol. Int. 2005, 38, 249-256. [CrossRef]

4. Kalin, M.; Vizintin, J.; Barriga, J.; Vercammen, K.; van Acker, K.; Arnsek, A. The effect of doping elements and oil additives on the tribological performance of boundary-lubricated DLC/DLC contacts. Tribol. Lett. 2004, 17, 679-688. [CrossRef]

5. Neville, A.; Morina, A.; Haque, T.; Voong, M. Compatibility between tribological surfaces and lubricant additives-How friction and wear reduction can be controlled by surface/lube synergies. Tribol. Int. 2007, 40, 1680-1695. [CrossRef]

6. Equey, S.; Roos, S.; Mueller, U.; Hauert, R.; Spencer, N.D.; Crockett, R. Tribofilm formation from ZnDTP on diamond-like carbon. Wear 2008, 264, 316-321. [CrossRef]

7. Topolovec-Miklozic, K.; Lockwood, F.; Spikes, H. Behaviour of boundary lubricating additives on DLC coatings. Wear 2008, 265, 1893-1901. [CrossRef] 
8. Kalin, M.; Roman, E.; Ozbolt, L.; Vizintin, J. Metal-doped (Ti, WC) diamond-like-carbon coatings: Reactions with extreme-pressure oil additives under tribological and static conditions. Thin Solid Films 2010, 518, 4336-4344. [CrossRef]

9. Tasdemir, H.A.; Wakayama, M.; Tokoroyama, T.; Kousaka, H.; Umehara, N.; Mabuchi, Y.; Higuchi, T. The effect of oil temperature and additive concentration on the wear of non-hydrogenated DLC coating. Tribol. Int. 2014, 77, 65-71. [CrossRef]

10. Tang, J.; Ding, Q.; Zhang, G.; Hu, L. The Influence of Total Acid Number of Ester Oil in Tribological Behavior of DLC Contacts. Tribol. Trans. 2015, 58, 849-858. [CrossRef]

11. Kalin, M. Designing tribological interface for efficient and green DLC lubrication: The role of coatings and lubricants. Tribol. Online 2012, 7, 112-118. [CrossRef]

12. Kalin, M. Traditional problems, yet new challenges, in lubrication science. Lubr. Sci. 2013, 25, $249-250$. [CrossRef]

13. Kalin, M.; Kogovsek, J.; Remskar, M. Nanoparticles as novel lubricating additives in a green, physically based lubrication technology for DLC coatings. Wear 2013, 303, 480-485. [CrossRef]

14. Kogovsek, J.; Remskar, M.; Kalin, M. Lubrication of DLC-coated surfaces with $\mathrm{MoS}_{2}$ nanotubes in all lubrication regimes: Surface roughness and running-in effects. Wear 2013, 303, 361-370. [CrossRef]

15. Zeng, Q.; Yu, F.; Dong, G. Superlubricity behaviors of $\mathrm{Si}_{3} \mathrm{~N}_{4}$ /DLC Films under PAO oil with nano boron nitride additive lubrication. Surf. Interface Anal. 2013, 45, 1283-1290. [CrossRef]

16. Kalin, M.; Kogovsek, J.; Kovac, J.; Remskar, M. The Formation of Tribofilms of $\mathrm{MoS}_{2}$ Nanotubes on Steel and DLC-Coated Surfaces. Tribol. Lett. 2014, 55, 381-391. [CrossRef]

17. Kogovsek, J.; Kalin, M. Various $\mathrm{MoS}_{2-}, \mathrm{WS}_{2-}$ and C-Based Micro- and Nanoparticles in Boundary Lubrication. Tribol. Lett. 2014, 53, 585-597. [CrossRef]

18. Zhang, L.; Pu, J.; Wang, L.; Xue, Q. Frictional dependence of graphene and carbon nanotube in diamond-like carbon/ionic liquids hybrid films in vacuum. Carbon 2014, 80, 734-745. [CrossRef]

19. Zhang, L.; Pu, J.; Wang, L.; Xue, Q. Synergistic Effect of Hybrid Carbon Nanotube-Graphene Oxide as Nanoadditive Enhancing the Frictional Properties of Ionic Liquids in High Vacuum. ACS Appl. Mater. Interfaces 2015, 7, 8592-8600. [CrossRef] [PubMed]

20. Rapoport, L.; Leshchinsky, V.; Lapsker, I.; Volovik, Y.; Nepomnyashchy, O.; Lvovsky, M.; Popovitz-Biro, R.; Feldman, Y.; Tenne, R. Tribological properties of $\mathrm{WS}_{2}$ nanoparticles under mixed lubrication. Wear 2003, 255, 785-793. [CrossRef]

21. Kato, H.; Komai, K. Tribofilm formation and mild wear by tribo-sintering of nanometer-sized oxide particles on rubbing steel surfaces. Wear 2007, 262, 36-41. [CrossRef]

22. Battez, A.H.; Gonzalez, R.; Viesca, J.L.; Fernandez, J.E.; Fernandez, J.M.D.; Machado, A.; Chou, R.; Riba, J. $\mathrm{CuO}, \mathrm{ZrO}_{2}$ and $\mathrm{ZnO}$ nanoparticles as antiwear additive in oil lubricants. Wear 2008, 265, 422-428. [CrossRef]

23. Zhang, S.; Hu, L.; Wang, H.; Feng, D. The anti-seizure effect of Ag nanoparticles additive in multialkylated cyclopentanes oil under vacuum condition. Tribol. Int. 2012, 55, 1-6. [CrossRef]

24. Dai, W.; Kheireddin, B.; Gao, H.; Liang, H. Roles of nanoparticles in oil lubrication. Tribol. Int. 2016, 102, 88-98. [CrossRef]

25. Zhang, S.; Hu, L.; Feng, D.; Wang, H. Anti-wear and friction-reduction mechanism of Sn and Fe nanoparticles as additives of multialkylated cyclopentanes under vacuum condition. Vacuum 2013, 87, 75-80. [CrossRef]

26. Guo, D.; Xie, G.; Luo, J. Mechanical properties of nanoparticles: Basics and applications. J. Phys. D Appl. Phys. 2014, 47, 013001. [CrossRef]

27. Tomala, A.; Vengudusamy, B.; Ripoll, M.R.; Suarez, A.N.; Remskar, M.; Rosentsveig, R. Interaction Between Selected $\mathrm{MoS}_{2}$ Nanoparticles and ZDDP Tribofilms. Tribol. Lett. 2015, 59, 1-18. [CrossRef]

28. Kaplan-Ashiri, I.; Tenne, R. On the Mechanical Properties of $\mathrm{WS}_{2}$ and $\mathrm{MoS}_{2}$ Nanotubes and Fullerene-Like Nanoparticles: In Situ Electron Microscopy Measurements. JOM 2016, 68, 151-167. [CrossRef]

29. Berman, D.; Deshmukh, S.A.; Sankaranarayanan, S.K.R.S.; Erdemir, A.; Sumant, A.V. Macroscale superlubricity enabled by graphene nanoscroll formation. Science 2015, 348, 1118-1122. [CrossRef] [PubMed]

30. Alazemi, A.A.; Etacheri, V.; Dysart, A.D.; Stacke, L.-E.; Pol, V.G.; Sadeghi, F. Ultrasmooth Submicrometer Carbon Spheres as Lubricant Additives for Friction and Wear Reduction. ACS Appl. Mater. Interfaces 2015, 7, 5514-5521. [PubMed]

31. Sun, Y.; Wu, H.; Li, M.; Meng, Q.; Gao, K.; Lü, X.; Liu, B. The Effect of $\mathrm{ZrO}_{2}$ Nanoparticles on the Microstructure and Properties of Sintered WC-Bronze-Based Diamond Composites. Materials 2016, 9, 343. 
32. Cui, L.; Lu, Z.; Wang, L. Toward low friction in high vacuum for hydrogenated diamondlike carbon by tailoring sliding interface. ACS Appl. Mater. Interfaces 2013, 5, 5889-5893. [CrossRef] [PubMed]

33. Stachowiak, G.W.; Batchelor, A.W. Elastohydrodynamic lubrication. In Engineering Tribology, 3rd ed.; Elsevier: Oxford, UK, 2005; pp. 287-362.

34. Archard, J.F.; Hirst, W. The wear of metals under unlubricated conditions. In Proceedings of the Royal Society of London Series a-Mathematical and Physical Sciences, London, UK, 2 August 1956; Volume 236, pp. 397-410.

35. Yonezawa, H.; Lee, K.-H.; Murase, K.; Sugimura, H. Self-assembled Multilayer Formed by Alternate Stacking of Zirconium and Terephthalic Acid Layers. Chem. Lett. 2006, 35, 1392-1393. [CrossRef]

36. Du, W.; Zhang, Y.; Wang, Y.; Liu, J.; Lu, H.; Hou, S.; Zhang, X. Designing synthesis and photocatalytic activities of $\mathrm{Gd} / \mathrm{ZrO}_{2}$ nanocomposite. J. Nanopart. Res. 2014, 16, 1-10. [CrossRef]

37. Silinskas, M.; Grigonis, A. Low energy post-growth irradiation of amorphous hydrogenated carbon (a-C:H) films. Diam. Relat. Mater. 2002, 11, 1026-1030. [CrossRef]

38. Popescu, A.; Stan, G.; Duta, L.; Nita, C.; Popescu, C.; Surdu, V.-A.; Husanu, M.-A.; Bita, B.; Ghisleni, R.; Himcinschi, C.; et al. The Role of Ambient Gas and Pressure on the Structuring of Hard Diamond-Like Carbon Films Synthesized by Pulsed Laser Deposition. Materials 2015, 8, 3284-3350. [CrossRef]

39. Jao, J.-Y.; Han, S.; Yen, C.-C.; Liu, Y.-C.; Chang, L.-S.; Chang, C.-L.; Shih, H.-C. Bias voltage effect on the structure and property of the (Ti:Cu)-DLC films fabricated by cathodic arc plasma. Diam. Relat. Mater. 2011, 20, 123-129. [CrossRef]

40. Ferrari, A.C.; Robertson, J. Interpretation of Raman spectra of disordered and amorphous carbon. Phys. Rev. B 2000, 61, 14095-14107. [CrossRef]

41. Ding, Q.; Wang, L.; Wang, Y.; Wang, S.C.; Hu, L.; Xue, Q. Improved Tribological Behavior of DLC Films Under Water Lubrication by Surface Texturing. Tribol. Lett. 2011, 41, 439-449. [CrossRef]

42. Ferrari, A.C.; Libassi, A.; Tanner, B.K.; Stolojan, V.; Yuan, J.; Brown, L.M.; Rodil, S.E.; Kleinsorge, B.; Robertson, J. Density, sp(3) fraction, and cross-sectional structure of amorphous carbon films determined by X-ray reflectivity and electron energy-loss spectroscopy. Phys. Rev. B 2000, 62, 11089-11103. [CrossRef]

43. Qi, J.; Wang, L.; Yan, F.; Xue, Q. The tribological performance of DLC-based coating under the solid-liquid lubrication system with sand-dust particles. Wear 2013, 297, 972-985. [CrossRef]

(C) 2016 by the authors; licensee MDPI, Basel, Switzerland. This article is an open access article distributed under the terms and conditions of the Creative Commons Attribution (CC-BY) license (http:/ / creativecommons.org/licenses/by/4.0/). 